\title{
New hydrodewaxing catalysts JSC "AZKiOS" for processing of waxy oil and diesel fuel
}

\begin{abstract}
JSC "Angarsk catalysts and organic synthesis plant" has the modern hydrodewaxing catalysts for production of the EURO diesel fuel and transformer oil. New generation of hydrodewaxing catalysts are the result of complex research. Researches of JSC "AZKiOS" performed optimization of ZSM-5 zeolite synthesis technology; the stage of promotor introduction in zeolite is performed. Increase of activity of the catalysts as a result of introduction in the promoted zeolite is established. As a result it has become possible to carry out the process at a lowered temperature, which leads to the increase in selectivity and operation cycle time.
\end{abstract}

\section{Keywords}

Transformer oil $\bullet$ Diesel fuel $\bullet$ Catalytic hydrodewaxing $\bullet$ Promotor $\bullet$ Pour point $\bullet$ Zeolite

(c) Versita Sp. z o.o.

\begin{tabular}{ll} 
Kiseleva T.P. ${ }^{1 *}$, & Posokhova O.M. ${ }^{1}$, \\
Reznichenko I.D. ${ }^{1}$, & Skornikova S.A. ${ }^{2}$ \\
Tselyutina M.I. & \\
\hline & \\
\hline JSC "Angarsk catalysts and organic & $\begin{array}{l}{ }^{2} \text { National Research Irkutsk State } \\
\text { Synthesis plant" }\end{array}$ \\
\hline
\end{tabular}

Received 15 December 2012

Accepted 22 January 2013

\section{Introduction}

The development of the hydrodewaxing catalyst for oil processing is mainly carried out in order to increase the depth of the processing, and for improvement of the quality of the oil products. Also, the climatic conditions of the Russian Federation create a high demand for waxy oil products. The most popular of these products are diesel fuels of winter grade and transformer oil, which ensuring a long and trouble-free functioning of the power equipment of energy sector objects.

In JSC "AZKiOS", the new generation of hydrodewaxing catalysts is developed for the production of oil products with a low pour point. The main feature of the new catalysts is a promoted zeolite of the ZSM- 5 type synthesized by hydrothermal treated silica gel.

\section{Experimental Procedure}

Dewaxing catalysts, as a rule, are zeolites that provide selective hydrocracking of paraffin hydrocarbons and an active component for the hydrogenation of unsaturated cracking products. Also, it contains the binding material, which determines the strength characteristics of the catalysts [1]. The dewaxing catalyst samples were prepared using the high-silica ZSM- 5 zeolite, produced from the following molar structure: $50 \mathrm{SiO}_{2} \cdot \mathrm{Al}_{2} \mathrm{O}_{3} \cdot 4 \mathrm{Na}_{2} \mathrm{O}$. The procedure for this zeolite synthesis includes a stage of hydrothermal pre-treatment of silica gel within 12-18 hours in the alkaline medium, with the subsequent additional load of reagents. The crystallization process is completed through autoclaving at a temperature of $170{ }^{\circ} \mathrm{C}$ for $48-72$ hours. The synthesized zeolite was decationized by a 2 -fold ionic exchange with an ammonium nitrate solution and a subsequent filtration. The promoting $\mathrm{Me}^{2+}$ component was introduced into the zeolite by a third ionic exchange. Preparation of the catalyst support was performed by using kneaded technology in which a mixture of promoted zeolite with oxide of aluminum and addition of the stabilizing agent - boron oxide are used. Then, the support was impregnated with the solution containing a hydrogenating component - Pt (chloroplatinic acid, $6 \mathrm{~g} / \mathrm{l}$ ) and Mo (ammonium molybdate, $100 \mathrm{~g} / \mathrm{l})$. After the impregnation step, the catalysts were calcined at $480^{\circ} \mathrm{C}$.

The phase structure of zeolites and catalysts samples was determined using $\mathrm{X}$-ray phase analysis on the Shimadzu Maxima XRD 7000 diffractometer with the copper anode and the monochromator on the diffracted bunch. The voltage was $40 \mathrm{kV}$ and current was $50 \mathrm{~mA}$. The diffraction patterns were recorded by scanning at an angle range from $5^{\circ}$ to $60^{\circ}$. The results showed that the zeolites samples have the structure of ZSM- 5 according to data [2] on the overall diffraction picture.

The morphology of zeolites and silica gel were studied using a dual-beam scanning (electronic and ionic) microscope JEOL JIB-Z4500 (Japan). Powders were placed on carrying-out adhesive tape, and then samples were removed at a voltage of $30-40 \mathrm{kV}$, modes of recording are specified in the associated figures (Figures 2-4).

The textural characteristics of the prepared samples of silica gel, zeolites and catalysts were studied using a low-temperature nitrogen adsorption technique based on measurement of adsorbed gas volume in static conditions at a temperature of $77.35 \mathrm{~K}$. Isotherms of adsorption were recorded using ASAP 2010M (Micromeritics) instrument. Calculations of specific surface area were carried out on the constructed site of an 
isotherm of nitrogen adsorption at five values of relative pressure $\left(P / P_{0}\right) 0.06 ; 0.08 ; 0.10 ; 0.12 ; 0.16 ; 0.20$ by BET method.

The catalytic activity measurement was performed on a pilot setup in a flow reactor packed with $100 \mathrm{~cm}^{3}$ of the catalyst using real raw materials - summer grade diesel fuel with the pour point of $-14^{\circ} \mathrm{C}$ and vacuum distillate $-280^{\circ} \mathrm{C}+$ hydrocracking fraction with the pour point $11^{\circ} \mathrm{C}$.

Experiments were carried out at: $\mathrm{T}=295-360{ }^{\circ} \mathrm{C}, \mathrm{P}=3.0$ MPa, $\mathrm{H}_{2} /$ feed ratio $=1000 \mathrm{~nm}^{3} / \mathrm{m}^{3}$, LHSV $=1.0-2.0 \mathrm{~h}^{-1}($ Table 1$)$ and at $\mathrm{T}=270-320^{\circ} \mathrm{C}, \mathrm{P}=4.0 \mathrm{MPa}, \mathrm{H}_{2} /$ feed ratio $=1500 \mathrm{~nm}^{3} / \mathrm{m}^{3}$, LHSV $=1.2 \mathrm{~h}^{-1}$ (Table 2).

Activity was estimated by:

- the yield of $180{ }^{\circ} \mathrm{C}^{+}$fraction from hydrogenation product for diesel fuel and $280{ }^{\circ} \mathrm{C}^{+}$for transformer oil in terms of the feed;

- the pour point of the target fraction.

\section{Results and Discussion}

Since catalytic properties of zeolites in transformation of n-paraffins are strongly affected by their pore structure, development of synthesis procedures allowing the control of crystallinity and porosity of zeolites is very important [3]. Figure 1 demonstrates the influence of hydrothermal treatment of silica gel in the alkaline medium duration on its porous structure. When carrying out the process within 6 hours, the pores radius increases from $20-45 \AA$ to $30-90 \AA$. A further increase of silica gel treatment results in the pore size growth up to $100 \AA$ or greater. After 12 hours of treatment, the quantity of a pores with a radius more than $100 \AA$ was $22 \%$, after 18 hours the quantity increased to $39 \%$, and finally after 24 hours the quantity was $49 \%$.

The samples of silica gel previously hydrothermally treated within 12, 18 and 24 hours were used in the synthesis of zeolites for dewaxing catalysts. It is shown that irrespective of silica gel treatment duration, a well crystallized zeolite is formed within 48 hours. Therefore, we chose the optimum time of hydrothermal processing of silica gel which, in our opinion, takes 12-18 hours. This conclusion is confirmed by the experimental data obtained

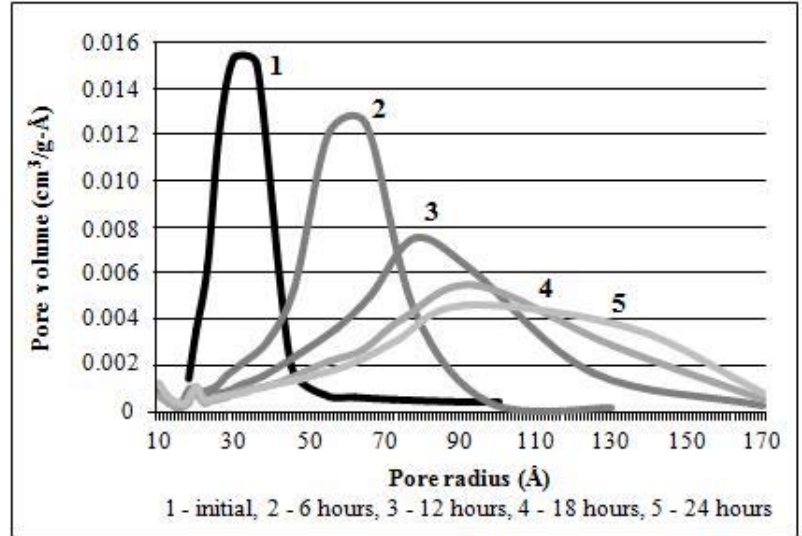

Figure 1. The influence of the silica gel hydrothermal treatment duration on its porous structure. by electron microscopy analysis (Figure 2-4). Figure 2 shows the electron micrograph of silica gel sample after 18 hours of hydrothermal treatment. As a result of the use of this silica gel as

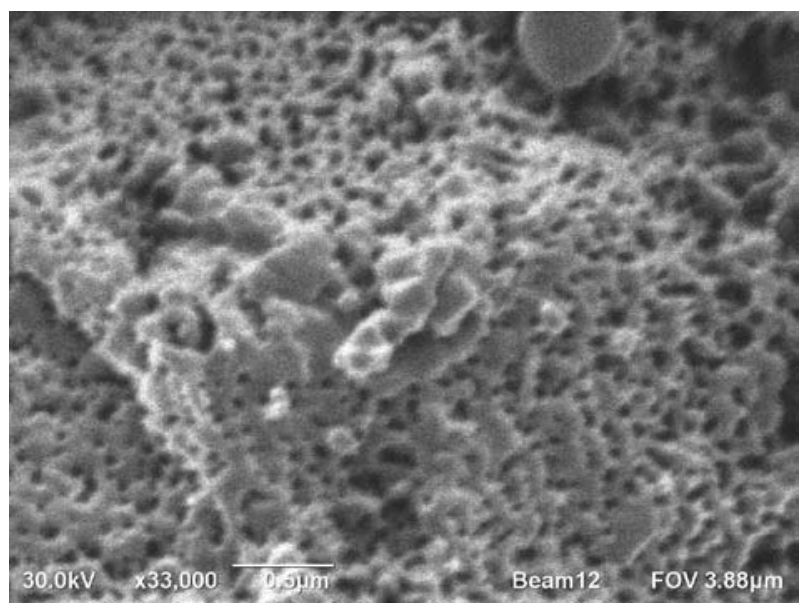

Figure 2. Electron micrograph of the silica gel sample after 18 hours of hydrothermal treatment.

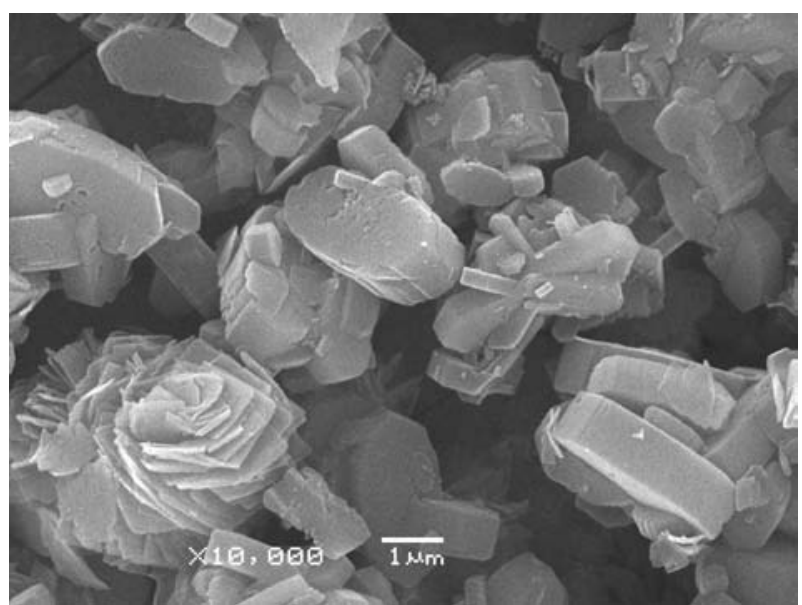

Figure 3. Electron micrograph of the zeolite synthesized within 120 hours on silica without hydrothermal treatment.

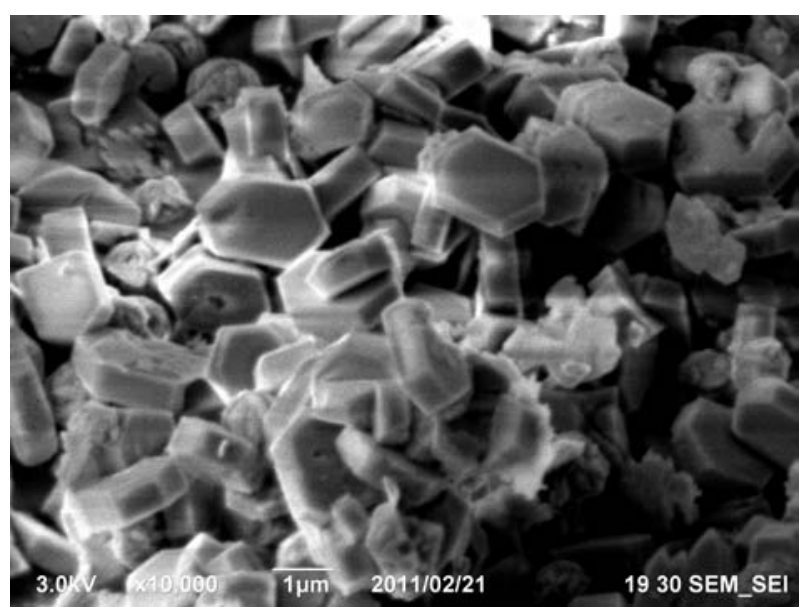

Figure 4. Electron micrograph of the zeolite synthesized within 48 hours on hydrothermal treatment silica. 
a raw source of silicon, the ZSM- 5 zeolite can be created in 48 hours. When the silica gel did not have previous hydrothermal processing, a ZSM- 5 zeolite is formed in 120 hours. Thus, silica gel hydrothermal treatment processing allows the reduction of zeolite synthesis time considerably. Besides, it was established that as a result of synthesis on previously processed silica gel, there is a decrease in the size of zeolite crystallites. The morphology of the zeolite samples is given in Figures 3 and 4 .

The catalyst samples synthesized on the basis of the promoted zeolite, produced from the hydrothermal treated silica gel according to [4] revealed high activity and selectivity in hydrodewaxing reaction. When carrying out the pilot tests, the catalysts of selective hydrocracking (JSC "AZKiOS") were used as models of comparison.

The DEP-1 $\left(5 \% \mathrm{MoO}_{3}\right)$ catalyst allows to produce the EURO diesel fuel (a class 4, a type I) in accordance with GOST R 523682005 (EN 590:2004) with a pour point of-52 ${ }^{\circ} \mathrm{C}$ at a process temperature of $330{ }^{\circ} \mathrm{C}$. Use of this catalyst in the course of hydrodewaxing of vacuum distillate allows for an increase in the yield by $10 \%$ compared to a basis of transformer oil, with pour point below $-59^{\circ} \mathrm{C}$, in comparison with the SGK- 5 catalyst now in use.

On the DEP-2 (0,3\% Pt) catalyst, at the process temperature of $295^{\circ} \mathrm{C}$, the EURO diesel fuel (class 3, type III) with a pour point of $-46^{\circ} \mathrm{C}$ is obtained, and at the process temperature of $300{ }^{\circ} \mathrm{C}$ - the EURO diesel fuel (class 4,type III) with a pour point of -65 ${ }^{\circ} \mathrm{C}$. In case of e DEP-2 catalyst, in the course of hydrodewaxing of vacuum distillate, the yield of a basis of transformer oil at the process temperature of $290{ }^{\circ} \mathrm{C}$ is $75.3 \%$, which is also $10 \%$ higher than on the industrial SGK- 5 catalyst.

Production of the target fractions on DEP-1 and DEP-2 catalysts provided at lowered temperatures, in comparison with SGK catalysts being successfully operated for a long time at many refineries. In this regard it is possible to assume that the DEP new catalysts possess more considerable catalytic capabilities. Testing the stability of these catalysts is necessary before the introduction on plants. For this reason, further tests will research long-term stability. The catalytic testing data on the dewaxing catalysts, in the course of receiving diesel fuel is given in Table 1 . Table 2 shows the data in the course of a basis of transformer oil production.

\section{Conclusions}

As a result of this complex research, JSC "AZKiOS" has the modern catalysts of the DEP series for the process of producing the EURO diesel fuel and transformer oil. The use of the new generation of hydrodewaxing catalysts JSC "AZKiOS" allows

Table 1. The catalytic activity of the samples in diesel EURO GOST R 52368-2005 (EN 590:2004) production.

\begin{tabular}{|c|c|c|c|c|c|c|}
\hline Catalyst & SGK-1 & \multicolumn{2}{|c|}{ DEP-1 } & \multicolumn{3}{|c|}{ DEP-2 } \\
\hline Fuel diesel EURO & $\begin{array}{c}\text { class } 2 \\
\text { type I }\end{array}$ & \multicolumn{2}{|c|}{$\begin{array}{c}\text { class } 4 \\
\text { type I }\end{array}$} & \multirow{2}{*}{\multicolumn{2}{|c|}{$\begin{array}{c}\text { class } 3 \\
\text { type III } \\
20\end{array}$}} & \multirow{2}{*}{$\begin{array}{c}\text { class } 4 \\
\text { type III } \\
20\end{array}$} \\
\hline Sulfur in the feed, ppm & 330 & 330 & & & & \\
\hline \multicolumn{7}{|l|}{ Process parameters } \\
\hline Pressure, MPa & 3.0 & 3.0 & 3.0 & 3.0 & 3.0 & 3.0 \\
\hline $\mathrm{H}_{2} /$ feed, $\mathrm{nm}^{3} / \mathrm{m}^{3}$ & 1000 & 1000 & 1000 & 1000 & 1000 & 1000 \\
\hline LHSV, $\mathrm{h}^{-1}$ & 1.0 & 1.0 & 2.0 & 1.0 & 2.0 & 1.0 \\
\hline Temperature, ${ }^{\circ} \mathrm{C}$ & 360 & 330 & 360 & 295 & 300 & 300 \\
\hline \multicolumn{7}{|l|}{ Product Properties } \\
\hline Yield of $180^{\circ} \mathrm{C}^{+}$fraction, $\%$ & 79 & 89 & 81 & 91 & 89 & 80 \\
\hline Pour point, ${ }^{\circ} \mathrm{C}$ & -42 & -52 & -55 & -46 & -48 & -65 \\
\hline
\end{tabular}

Table 2. The catalytic activity of the samples in transformer oil production.

\begin{tabular}{|c|c|c|c|c|c|c|}
\hline \multirow[t]{2}{*}{$\begin{array}{c}\text { Process } \\
\text { temperature, }{ }^{\circ} \mathrm{C}\end{array}$} & \multicolumn{2}{|c|}{ SGK-5 } & \multicolumn{2}{|c|}{ DEP-1 } & \multicolumn{2}{|c|}{ DEP-2 } \\
\hline & $\begin{array}{l}\text { Yield of } 280{ }^{\circ} \mathrm{C}^{+} \\
\text {fraction, } \%\end{array}$ & $\begin{array}{c}\text { Pour point, } \\
{ }^{\circ} \mathrm{C}\end{array}$ & $\begin{array}{l}\text { Yield of } 280{ }^{\circ} \mathrm{C}^{+} \\
\text {fraction, } \%\end{array}$ & $\begin{array}{c}\text { Pour point, } \\
{ }^{\circ} \mathrm{C}\end{array}$ & $\begin{array}{l}\text { Yield of } 280{ }^{\circ} \mathrm{C}^{+} \\
\text {fraction, } \%\end{array}$ & $\begin{array}{l}\text { Pour point, } \\
{ }^{\circ} \mathrm{C}\end{array}$ \\
\hline 320 & 48.9 & -64 & 57.9 & -63 & & \\
\hline 300 & 53.4 & -64 & 70.7 & -61 & 70.9 & -62 \\
\hline 290 & 62.3 & -63 & 73.6 & -58 & 75.3 & -54 \\
\hline 280 & 64.4 & -56 & 74.5 & -59 & 75.5 & -23 \\
\hline 270 & 65.9 & -32 & 75.7 & -37 & & \\
\hline
\end{tabular}


production of high-quality waxy diesel fuels and oils in mild conditions.

The catalytic dewaxing processes have found, in recent years, to have an increase in application because of the simplicity

\section{References}

[1] Konovalchik O.D., Poezd D.F., Krasilnikova L.A., Zelentsov J.N., Porublev M.A., Babikov A.F., Yaskin V.P., Catalysts and processes hydrodewaxing petroleum fractions. Thematic Review. CNIITEneftehim, 1994.

[2] Lyadin N.M., Pushkarev J.N., Barkov V.I., Havkin V.A., Gulyaev L.A., Vinogradova N.Y., World oil products., 2008, № 4 , p.3. of the technological procedure. When integrated with process of deep hydrotreating, there is the possibility to produce fuels and oils necessary of the modern ecological and operational requirements.

[3] Bushuev J.G., Zeolites. Computer modeling of zeolite materials. Ivanovo State University of Chemical Technology. 2011, $104 \mathrm{pp}$

[4] Patent No.2457179 Method of preparation of high-silica zeolite / Reznichenko I.D., Tselyutina M.I., Posokhova O.M., Aliev R.R., Skornikova S.A., Gizetdinova A.F., Kiseleva T.P. 2010. 